\title{
Infant feeding information, attitudes and practices: a longitudinal survey in central Nepal
}

\author{
Rajendra Karkee ${ }^{1 *}$, Andy H Lee ${ }^{2}$, Vishnu Khanal ${ }^{3}$ and Colin W Binns ${ }^{2}$
}

\begin{abstract}
Background: Infant feeding is governed by environmental as well as cultural factors. Breastfeeding knowledge and attitudes are known to be associated with breastfeeding duration. This study investigated breastfeeding information, attitudes and supplementary feeding in the central hills district of Nepal.

Methods: A community-based prospective cohort study of 701 pregnant women was conducted. Information on breastfeeding attitudes, feeding practices and supplementary feeding was sought from the cohort at 4 weeks, 12 weeks and 22 weeks postpartum through repeated interviews using validated questionnaires.

Results: Average duration of intended breastfeeding was 28 months (SD 7.9) and average target time to introduce solid foods was 6.1 months (SD 1.2). About 80\% of women reported their husband, mother/mother-in-law preferred breastfeeding. Eleven percent of the cohort said that breastfeeding was not enjoyable. At 12 weeks and 22 weeks after birth, about a quarter (24.8\%) and half (52.8\%) of the infants were introduced cow/buffalo milk, respectively, while only $6.3 \%$ and $13.4 \%$ of them were given infant formula. Overall, any breastfeeding rate remained high at over $98 \%$ throughout the follow up period.
\end{abstract}

Conclusions: Breastfeeding attitudes were encouraging in this population. Breastfeeding was almost universal. Use of infant formula was quite low, whereas cow or buffalo milk appeared to be popular supplementary foods.

Keywords: Attitude, Breastfeeding, Feeding practice, Nepal

\section{Background}

Under-nutrition has a major role on child mortality and morbidity, posing a challenge to achieve the Millennium Development Goal 4 [1]. While suboptimal breastfeeding contributes to child under-nutrition [2], there are large variations in breastfeeding rates between countries [3]. In Nepal, breastfeeding is almost universal with reported rates of $98 \%$ and $70 \%$ for infants under six months being ever-breastfed and exclusively breastfed, respectively [4]. Breastfeeding attitudes of mothers and their intention to breastfeed are known to be associated with the duration of breastfeeding $[5,6]$. Such attitude and knowledge of breastfeeding can be affected by maternal, cultural and environmental factors [7-9].

Nepal is diversified in terms of ethnicity and ecology. The country has three ecological regions (Mountain, Hill and Plain) extending from east to west with 105 recorded

\footnotetext{
* Correspondence: rkarkee@gmail.com

${ }^{1}$ School of Public Health and Community Medicine, BP Koirala Institute of Health Sciences, Dharan, Nepal

Full list of author information is available at the end of the article
}

ethnicities [4]. Existing information on infant feeding in Nepal has been largely derived from the Nepal Demographic and Health Surveys (DHS) [10]. As part of a large prospective cohort study in central Nepal, we report infant feeding information, attitudes and practices in this article.

\section{Methods}

\section{Study design and location}

This study was conducted in Kaski, a centrally located hills district of Nepal. The district has a 75\% female literacy rate with 138,000 expected pregnancies per annum [11]. About half (49\%) of the population belong to the upper caste of Indo-Aryan origin and about one-third (34\%) belong to the Janajati caste who are mainly Tibeto-Burman people [11]. The rest (17\%) are lower caste people also of Indo-Aryan origin.

This study is part of a large community-based prospective cohort study undertaken between December 2011 and November 2012 to investigate the utilisation of maternity 
services. Details about the sampling design and procedure have been described elsewhere [12,13]. Briefly, a cohort of 701 pregnant women of 5 months or more gestational age were recruited from the Kaski district and followed for six months after delivery.

\section{Data collection and ethics}

The questionnaire used in the face-to-face interview was adapted from the validated Nepal Demographic and Health Survey and another breastfeeding instrument [14], and was subsequently pretested on 25 postpartum women for cultural appropriateness, content validity and understanding; see Additional file 1. Fifteen female data enumerators conducted the baseline interview from December 2011 to January 2012 to collect information on sociodemographics and obstetric characteristics of the pregnant women. The cohort of participants was then followed up at 4 weeks, 12 weeks and 22 weeks postpartum through repeated household visits by the same enumerators. Infant feeding information, including breastfeeding knowledge and support, husband's and mother/mother-in-law's preferences and feeding plans, was collected at 4 weeks during the second visit. Attitude towards breastfeeding was asked at the third visit, perception of sufficiency of breast milk was solicited at 4 and 22 weeks, whereas supplementary feeding was assessed at all three follow-up visits.

The study was approved by the Human Research Ethics Committee of Curtin University (approval number HR 130/2011), Ethical Review Board of the Nepal Health Research Council (approval number 88/2011) and the District Public Health Office of Kaski. An information sheet was distributed and read to each participant before obtaining her signed or thumb-print consent. Confidentiality of the information provided was maintained throughout the study.

\section{Statistical analysis}

All data entry was performed by the first author, who further checked for correctness and consistency upon completion. Descriptive statistics were used to summarise the outcome variables and other variables of interest using the SPSS package version 20. Four levels of education were recorded: none, primary (1-5th grade), secondary (6-10th grade) and college (after 10th grade). Employment status was categorised as: employed (full-time salaried job), semi-employed (wage based labour, small business or employed abroad), and unemployed (agricultural, housewife or nothing). 'Breastfeeding information' was recorded as "none" if the woman did not receive such information from anywhere. Absence of 'encourage to breastfeed' meant there was no encouragement or motivation from anybody else to breastfeed after delivery. Similarly, lack of 'advice on feeding method' implied no one had advised the participant how to feed her newborn. Intended duration of breastfeeding and target time to introduce solid foods were initially recorded as continuous variables but recoded as categorical to facilitate analysis.

\section{Results}

\section{Participant profile}

Of the 639 women who took part in the second interview at 4 weeks after delivery, 615 and 515 participants were eventually followed up at the third (12 weeks) and fourth (22 weeks) interviews. Attrition was due to lost to follow up ( $\mathrm{n}=39)$ during the period and non-completers at 5 months $(n=85)$. Table 1 shows the socio-demographic characteristics of the cohort. At baseline about half the women were first time mothers, within the age range 2024 years, and belonged to the upper caste. Almost $80 \%$ of them were unemployed while the majority (70.8\%) received secondary or above education. These characteristics were similar at subsequent follow ups (Table 1). Moreover, no significant differences in these variables were found between drop outs and women remaining in the cohort at the two time points, suggesting that the loss-to-follow-up was random and no apparent bias was introduced through attrition.

Table 1 Characteristics of participants at 4, 12, and 22 weeks postpartum, Kaski District, Nepal

\begin{tabular}{|c|c|c|c|}
\hline & $\begin{array}{c}4 \text { weeks } \\
n=639\end{array}$ & $\begin{array}{c}12 \text { weeks } \\
n=615\end{array}$ & $\begin{array}{c}22 \text { weeks } \\
n=515\end{array}$ \\
\hline Characteristic & n (\%) & n (\%) & n (\%) \\
\hline \multicolumn{4}{|l|}{ Age (years) } \\
\hline $15-19$ & $91(14.2)$ & $91(15.0)$ & 75 (14.6) \\
\hline $20-24$ & $324(50.7)$ & $313(50.9)$ & $264(51.3)$ \\
\hline $25-40$ & $224(35.1)$ & $211(34.1)$ & $176(34.2)$ \\
\hline \multicolumn{4}{|l|}{ Parity } \\
\hline Primiparous & $329(51.5)$ & $318(51.7)$ & $275(53.4)$ \\
\hline Multiparous & $310(48.5)$ & $297(48.3)$ & 240 (46.6) \\
\hline \multicolumn{4}{|l|}{ Employment } \\
\hline Unemployed & $509(79.7)$ & $495(80.5)$ & $408(79.2)$ \\
\hline Semi-employed & $98(15.3)$ & $92(15.0)$ & $81(15.7)$ \\
\hline Employed & $32(5.0)$ & $28(4.6)$ & $26(5.0)$ \\
\hline \multicolumn{4}{|l|}{ Caste } \\
\hline Upper caste & $339(53.3)$ & $327(53.2)$ & $268(52.0)$ \\
\hline Janajati & $138(21.7)$ & $132(21.5)$ & $113(21.9)$ \\
\hline Lower caste & $159(25.0)$ & $153(24.9)$ & $131(99.4)$ \\
\hline \multicolumn{4}{|l|}{ Education } \\
\hline None & $53(8.3)$ & $53(8.6)$ & $44(8.5)$ \\
\hline Primary & $133(20.8)$ & $128(20.8)$ & 111 (21.6) \\
\hline Secondary & $238(37.2)$ & 234 (38.4) & 195 (37.9) \\
\hline College & 215 (33.6) & $200(32.5)$ & $165(32.0)$ \\
\hline
\end{tabular}


Table 2 Infant feeding information and attitudes, Kaski District, Nepal $(n=639)$

\begin{tabular}{l} 
Attitude \\
\hline Breastfeeding information* \\
None \\
Health personnel \\
Female community health volunteers \\
Family members \\
Others (relatives, media, self-study, etc.) \\
Intended breastfeeding duration \\
5-12 months \\
13-24 months \\
$25-60$ months \\
Mean (SD) months \\
Target time to introduce solid foods \\
3-5 months \\
6 months \\
7-12 months \\
Mean (SD) months \\
Decision on feeding method \\
Before becoming pregnant \\
Early in pregnancy \\
Late in pregnancy \\
After delivery \\
Honice on feeding method* \\
Hother/mother-in-law \\
None
\end{tabular}

Encourage to breastfeed after delivery*

None

Health personnel

Mother/mother-in-law

Husband

Mother/mother-in-law's preference

Prefers breastfeeding

Prefers bottle feeding

Do not care

Not discussed the matter

\section{Husband's preference}

Prefers breastfeeding

Prefers bottle feeding

Do not care

Not discussed the matter

n (\%)

Table 2 Infant feeding information and attitudes, Kaski District, Nepal $(n=639)$ (Continued)

\begin{tabular}{lcc}
\hline Attitude towards breastfeeding at $\mathbf{1 2}$ weeks $(\mathbf{n = 6 1 5 )}$ & & \\
Totally not enjoyable & 21 & $(3.3)$ \\
Not enjoyable & 50 & $(7.8)$ \\
Neutral & 132 & $(20.6)$ \\
Enjoyable & 316 & $(49.4)$ \\
Very enjoyable & 120 & $(18.8)$ \\
\hline *Multiple responses. & &
\end{tabular}

Infant feeding information and attitudes

As shown in Table 2, most of the mothers (73.6\%) had received information on breastfeeding. Their main source of information was from health personnel (39.6\%), followed by female community health volunteers $(33.5 \%)$ and family members (24.8\%). Often they had seen advertisements for infant formula (63.5\%). Table 3 shows that $85 \%$ of mothers perceived their breast milk was sufficient at 4 weeks but the prevalence decreased significantly to $54.7 \%$ at 22 weeks postpartum $(\mathrm{p}<0.001)$. In case of perceived insufficiency, about $80 \%$ of mothers at 4 weeks considered cow and/or buffalo milk as the main supplement, yet it reduced significantly to $63 \%$ at 22 weeks postpartum ( $<<0.001$ ).

The average duration of intended breastfeeding was 28 months (range 5 to 60 ) and more than $95 \%$ of participants intended to breastfeed longer than 12 months. The average time planned to introduce solid foods was at 6 months (range 3 to 12) with 12\% of women intending to do so after 6 months. About $55 \%$ of women decided what to feed their infant after giving birth. Although onethird of women (32.2\%) reported that no one had advised them on feeding method, $43 \%$ said that they had been counselled by health personnel. In particular, about half the women (52.6\%) were encouraged to breastfeed by health personnel after delivery. Moreover, approximately $80 \%$ of women perceived that their husband, mother or mother-in-law would prefer breastfeeding. Eleven percent

Table 3 Perceived sufficiency of breastmilk at 4 and 22 weeks postpartum, Kaski District, Nepal

\begin{tabular}{lccc}
\hline Perception & $\begin{array}{c}\mathbf{4} \text { weeks } \\
\mathbf{n = 6 3 9} \\
\mathbf{n}(\%)\end{array}$ & $\begin{array}{c}\mathbf{2 2} \text { weeks } \\
\mathbf{n}=\mathbf{5 1 5} \\
\mathbf{n}(\%)\end{array}$ & $\mathbf{P}$ \\
\hline Breastmilk sufficient & & & \\
$\quad$ No & $96(15.0)$ & $233(45.3)$ & \\
$\quad$ Yes & $543(85.0)$ & $282((54.7)$ & $<0.001$ \\
Main alternative if insufficient & & & \\
$\quad$ Cow/buffalo milk & $508(79.5)$ & $325(63.1)$ & $<0.001$ \\
$\quad$ Infant formula & $118(18.5)$ & $91(17.7)$ & 0.65 \\
$\quad$ Porridge & $13(2.0)$ & $99(19.2)$ & $<0.001$ \\
\hline
\end{tabular}


of mothers reported that breastfeeding was not enjoyable at 12 weeks postpartum.

\section{Infant feeding}

Table 4 presents the infant feeding practices by the Nepalese women. At birth, 581 of the 639 mothers fed colostrum as the newborn's first feed, giving a breastfeeding rate of $90.9 \%$. Almost all babies (99.3\%) were breastfed at 4 weeks and the 'any breastfeeding rate' remained constant at $98 \%$ throughout the follow up until 22 weeks. Cow or buffalo milk was introduced to about a quarter $(24.8 \%)$ and half $(52.8 \%)$ of the infants at 12 weeks and 22 weeks, respectively, whereas infant formula was only fed as supplementary food to $6.3 \%$ and $13.4 \%$ of infants at the same time.

\section{Discussion}

This study confirmed the positive attitudes of women towards breastfeeding in central Nepal. They also appeared to receive good support and encouragement to breastfeed from health workers and family members. Indeed, birth preparedness programs have been implemented in the study district as part of the national mother and newborn survival strategy. This program incorporated lactation counselling sessions to pregnant women at both health facility and community levels. As observed in the present study, about one-third of women obtained such breastfeeding information from either female community health volunteers or health facility personnel, while about half of them received encouragement to breastfeed from health workers.

Breastfeeding is traditionally a popular practice in Nepalese society and mothers are committed to breastfeed for a long duration. This study found that almost all infants (98\%) have been breastfed and their mothers intended to continue breastfeeding for an average of 28 months. Breastfeeding intention and social support have been found to be positively associated with breastfeeding duration [5]. In fact, the NDHS 2011 reported that half the children surveyed were breastfed up to 34 months [4]. A number of factors including unemployment and reliance on breast milk as the readily available infant

Table 4 Infant feeding practices, Kaski District, Nepal

\begin{tabular}{lcccc}
\hline & $\begin{array}{c}\text { At birth } \\
\mathbf{n = 6 3 9} \\
\text { Feeding method }\end{array}$ & $\begin{array}{c}\mathbf{4} \text { weeks } \\
\mathbf{n}=\mathbf{6 3 9}\end{array}$ & $\begin{array}{c}\mathbf{1 2} \text { weeks } \\
\mathbf{n = 6 1 5}\end{array}$ & $\begin{array}{c}\mathbf{2 2} \text { weeks } \\
\mathbf{n}=\mathbf{5 1 5}\end{array}$ \\
\hline Breastfeeding & $581(90.9)$ & $635(99.3)$ & $607(98.6)$ & $505(98.0)$ \\
Cow/buffalo milk & $4(0.6)$ & $92(14.4)$ & $153(24.8)$ & $272(52.8)$ \\
Infant formula & $43(6.7)$ & $11(1.7)$ & $39(6.3)$ & $69(13.4)$ \\
Solids & 0 & 0 & $23(3.7)$ & $156(30.3)$ \\
Other fluids & $11(1.7)$ & 0 & 0 & 0 \\
\hline
\end{tabular}

food might have contributed to the continuing breastfeeding practice.

Many mothers perceived that breast milk was insufficient at 22 weeks and that cow or buffalo milk could be given as supplementary feeds. A cross-sectional study in urban Nepal reported that the main reason for introducing other foods before six months of age was perceived insufficient breast milk [15]. Another qualitative study of working mothers in peri-urban Kathmandu similarly concluded that mothers supplemented breastfeeding with infant formula and solid foods if they felt they did not have enough breast milk for their infants [16]. Unlike infant formula, cow and/or buffalo milk is locally available in both rural and urban areas. It is therefore not surprising to find that over half $(52.8 \%)$ of the cohort of infants were given cow and/or buffalo milk at 22 weeks. The low usage of infant formula in urban areas of Nepal had been previously reported [17].

A major strength of this study was the prospective assessment of infant feeding attitudes from a large cohort of newly delivered women recruited from the community. Although maternal recall bias of infant feeding is expected to be minimal [18], generalizability of the findings to other parts of the country remains a limitation because the study was conducted in the central hills district of Nepal only. The Kaski district ranks third in terms of the human development index among 75 districts in Nepal with relatively high adult literacy rate (82\% compared to $60.9 \%$ for Nepal overall), and 'Gurung' as the main Janajati people inhabiting this district [19]. Further qualitative studies are needed to explore the reasons behind their perceptions and attitudes on breastfeeding as well as the early introduction of supplementary feeds, together with quantitative analysis of the potential influencing factors, so that appropriate interventions can be developed to encourage breastfeeding for vulnerable population subgroups.

\section{Conclusions}

Breastfeeding practices were encouraging in this population except the early introduction of supplementary feeds before 22 weeks. Average intention to breastfeed was 26 months. Use of infant formula was quite low, but supplementing breast milk with cow/buffalo milk was popular.

\section{Additional file}

Additional file 1: Questionnaire: Infant feeding information and

practices.

\section{Competing interests}

The authors declare that they have no competing interests. 


\section{Authors' contributions}

RK managed the project and coordinated data collection, performed data entry and drafted the manuscript. AHL contributed to data analysis and revision of the manuscript. VK assisted with data collection and project development. CWB developed the study protocol and revised the manuscript. All four authors read and approved the final version for publication.

\section{Acknowledgements}

This project was partially supported by an Australian Development Scholarship awarded to the first author. The authors are grateful to the assistance provided by staff of the District Public Health Office of Kaski, data enumerators, and participants who kindly gave their time for the interviews.

\section{Author details}

${ }^{1}$ School of Public Health and Community Medicine, BP Koirala Institute of Health Sciences, Dharan, Nepal. ${ }^{2}$ School of Public Health, Curtin University, Perth, WA, Australia. ${ }^{3}$ Sanjeevani College of Medical Sciences, Butwal, Rupandehi, Nepal.

Received: 9 December 2013 Accepted: 24 August 2014

Published: 28 August 2014

\section{References}

1. Funds UNC's: Improving child nutrition: The achievable imperative for global progress. United Nations Plaza, New York: United Nations Children's Fund; 2013.

2. Black RE, Victora CG, Walker SP, Bhutta ZA, Christian P, de Onis M, Ezzati M, Grantham-McGregor S, Katz J, Martorell R, Uauy R: Maternal and child undernutrition and overweight in low-income and middle-income countries. The Lancet 2013, 382(9890):427-451

3. Funds UNC's: The state of the world's children 2014. New York: United Nations Children's Funds; 2014.

4. Ministry of Health and Population [Nepal], New ERA, ICF International Inc: Nepal Demographic and Health Survey 2011. Kathmandu, Nepal and Calverton, Maryland: Ministry of Health and Population [Nepal], New ERA, and ICF International Inc; 2012.

5. Meedya S, Fahy K, Kable A: Factors that positively influence breastfeeding duration to 6 months: a literature review. Women Birth 2010, 23(4):135-145.

6. Lutsiv O, Pullenayegum E, Foster G, Vera C, Giglia L, Chapman B, Fusch C, McDonald SD: Women's intentions to breastfeed: a population-based cohort study. BJOG 2013, 120(12):1490-1499.

7. Scott JA, Binns CW, Oddy WH, Graham Kl: Predictors of breastfeeding duration: evidence from a cohort study. Pediatrics 2006, 117(4):e646-e655.

8. Bai Y, Middlestadt SE, Peng C-YJ, Fly AD: Predictors of continuation of exclusive breastfeeding for the first six months of life. Journal of Human Lactation 2010, 26(1):26-34.

9. de Jager E, Skouteris H, Broadbent J, Amir L, Mellor K: Psychosocial correlates of exclusive breastfeeding: a systematic review. Midwifery 2013, 29(5):506-518.

10. Pandey S, Tiwari K, Senarath U, Agho KE, Dibley MJ: Determinants of infant and young child feeding practices in Nepal: secondary data analysis of Demographic and Health Survey 2006. Food \& Nutrition Bulletin 2010, 31(2):334-351.

11. District Public Health Office Kaski: Annual Health Report of Kaski. Pokhara: Regional Health Directorate, Ministry of Health and Population, Government of Nepal; 2012.

12. Karkee $\mathrm{R}$, Lee $\mathrm{AH}$, Binns $\mathrm{CW}$ : Birth preparedness and skilled attendance at birth in Nepal: implications for achieving Millennium Development Goal 5. Midwifery 2013, 29(10):1206-1210.

13. Karkee $\mathrm{R}$, Lee $\mathrm{AH}$, Binns CW: Determinants of facility delivery after implementation of safer mother programme in Nepal: a prospective cohort study. BMC Pregnancy and Childbirth 2013, 13:193.

14. Duong DV, Binns CW, Lee AH: Breast-feeding initiation and exclusive breast-feeding in rural Vietnam. Public Health Nutrition 2004, 7(06):795-799.

15. Ulak M, Chandyo R, Mellander L, Shrestha P, Strand T: Infant feeding practices in Bhaktapur, Nepal: a cross-sectional, health facility based survey. Int Breastfeeding J 2014, 7:1.

16. Moffat T: Breastfeeding, wage labor, and insufficient milk in peri-urban Kathmandu Nepal. Medical Anthropology 2002, 21(2):207-230.

17. Chandrashekhar TS, Joshi HS, Binu V, Shankar PR, Rana MS, Ramachandran U: Breast-feeding initiation and determinants of exclusive breast-feeding - a questionnaire survey in an urban population of western Nepal. Public Health Nutrition 2007, 10(2):192-197.

18. Li R, Scanlon KS, Serdula MK: The validity and reliability of maternal recall of breastfeeding practice. Nutrition Reviews 2005, 63(4):103-110.

19. Central Bureau of Statistics: National Population and Housing Census 2011 Kathmandu: National Planning Commission Secretariat, Central Bureau of Statistics, Government of Nepal; 2012.

doi:10.1186/1746-4358-9-14

Cite this article as: Karkee et al:: Infant feeding information, attitudes and practices: a longitudinal survey in central Nepal. International Breastfeeding Journal 2014 9:14.

\section{Submit your next manuscript to BioMed Central and take full advantage of:}

- Convenient online submission

- Thorough peer review

- No space constraints or color figure charges

- Immediate publication on acceptance

- Inclusion in PubMed, CAS, Scopus and Google Scholar

- Research which is freely available for redistribution

Submit your manuscript at www.biomedcentral.com/submit
C Biomed Central 